References:

[1 Pan L, et al. Platelet-to-lymphocyte ratio and neutrophil-to-lymphocyte ratio associated with disease activity in patients with Takayasu's arteritis: a case-control study. BMJ Open 2017; 7: e014451

[2] Schmidt J, et al. Diagnostic features, treatment, and outcomes of Takayasu arteritis in a US cohort of 126 patients, Mayo Clin Proc. 2013; 88(8): 822-30 Disclosure of Interests: None declared

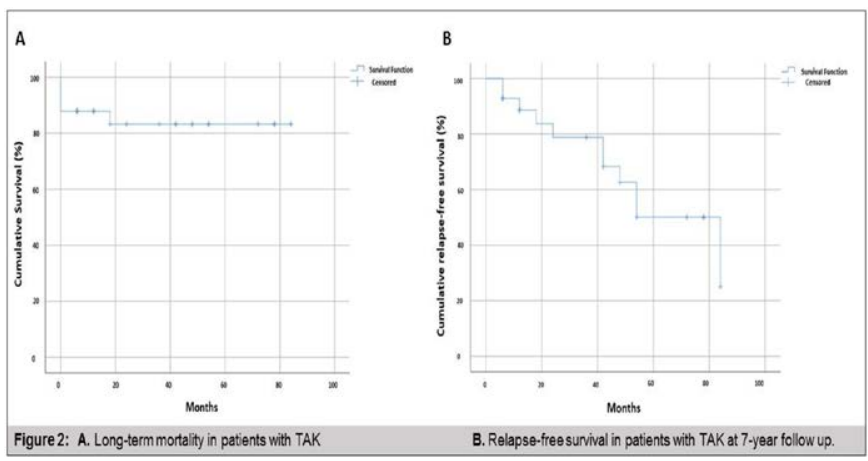

DOI: 10.1136/annrheumdis-2020-eular.3418

\section{AB0536 $\quad$ EFFECT OF HYDROXYCHLOROQUINE TREATMENT IN MUCOCUTANEOUS MANIFESTATIONS IN PATIENTS WITH BEHÇET'S SYNDROME}

F. Kerstens ${ }^{1}$, S. Mohamed ${ }^{1}$, I. Visman ${ }^{1}$, E. Turkstra ${ }^{1}$, C. Swearingen ${ }^{2}$, Y. Yazici ${ }^{2}$. ${ }^{1}$ ARC Reade, Amsterdam, Netherlands; ${ }^{2}$ NYU Langone Health, Hospital for Joint Diseases, New York, United States of America

Background: Behçet syndrome (BS) is a rare multisystemic vasculitis, most commonly seen in regions along the ancient Silk Road. It runs a relapsing and remitting course. Mucocutaneous disease, consisting of oral ulcers, genital ulcers and skin lesions is often reported. EULAR recommendations advise colchicine and topical agents for the treatment of these lesions. ${ }^{1}$ Not all patients respond adequately, thus, it is important to explore alternative treatment options.

Objectives: To study the efficacy of hydroxychloroquine (HCQ) $400 \mathrm{mg}$ daily in patients with mucocutaneous BS.

Methods: Data on all patients who presented at the outpatient Behçet clinic in New York were recorded. Patients with a first prescription with HCQ and a follow-up of 3 months (range: 2.75-41.2 months) were included. Patient reported outcomes BSAS and RAPID3 were used to evaluate the effect of HCQ. Results of all patients and of International Study Group (ISG) positive patients were analyzed separately using Wilcoxon rank tests.

Results: We included 94 patients with a first prescription of HCQ. 72 patients $(76.6 \%)$ fulfilled ISG criteria. Mean age was 36.1 years (SD 12.5), 76 patients $(80.9 \%)$ were female and 11 patients $(11.7 \%)$ were from Silk Road countries.

Mean duration until follow-up was 6.5 months (SD 5.7). Median BSAS scores in ISG+ patients at baseline did not differ significantly from ISG- patients, except for skin lesions (5.0 in ISG+ vs. 0.5 in ISG- $p=0.005$ ). BSAS scores at follow-up did not differ significantly (ISG+ vs. ISG-).

Median BSAS scores were significantly lower at follow-up compared to baseline for oral ulcers $(p=0.010)$, skin lesions $(p=0.018)$ and overall activity $(p=0.019)$. Regarding genital ulcers there was no significant result, due to only 37 patients

Table 1. Median BSAS scores of patients treated with HCQ.

\begin{tabular}{lccc}
\hline & $\begin{array}{c}\text { Baseline } \\
\text { (median, IQR) }\end{array}$ & $\begin{array}{c}\text { Follow-up 3 months } \\
\text { (median, IQR) }\end{array}$ & P-values \\
\hline All patients $(\mathbf{n = 9 4 )}$ & & & \\
Oral ulcers & $5.0(2.00-7.88)$ & $3.0(1.00-6.00)$ & $\mathbf{0 . 0 1 0}$ \\
Genital ulcers & $0.0(0.00-3.88)$ & $0.0(0.00-3.00)$ & 0.371 \\
Skin lesions & $5.0(1.25-7.00)$ & $2.5(0.00-7.00)$ & $\mathbf{0 . 0 1 8}$ \\
Overall activity & $5.5(4.00-8.00)$ & $5.0(2.00-7.25)$ & $\mathbf{0 . 0 1 9}$ \\
ISG+ patients $(\mathbf{n}=\mathbf{7 2})$ & & & \\
Oral ulcers & $5.25(2.00-7.63)$ & $3.25(1.00-6.00)$ & $\mathbf{0 . 0 0 7}$ \\
Genital ulcers & $0.5(0.00-4.00)$ & $0.0(0.00-3.00)$ & 0.684 \\
Skin lesions & $5.0(2.00-7.13)$ & $3.0(0.00-7.00)$ & $\mathbf{0 . 0 1 5}$ \\
Overall activity & $6.0(4.00-8.00)$ & $5.0(2.00-7.50)$ & 0.057 \\
\hline
\end{tabular}

reporting complaints of genital ulcers. Performing these analyses in ISG+ patients only did not change these results, except for BSAS overall activity, which lost significance $(p=0.057)$.

RAPID3 scores were not statistically different between baseline and follow-up (9.67 vs. 8.75, $p=0.145)$, nor were its separate components function $(p=0.67$ vs. $0.67,0.713)$, pain ( 4.0 vs. $4.0, p=0.157)$ and patient global (5.0 vs. 4.5 , $\mathrm{p}=0.095)$.

The majority of patients used prednisone at baseline $(58.5 \%)$ and at follow-up (57.4\%). In 15 patients, prednisone was stopped at follow up, in 13 patients it was started.

Conclusion: HCQ improves median BSAS scores for oral ulcers, skin lesions and overall activity at 3 months follow-up compared to baseline. These results were similar in ISG+ patients (except for overall activity). Additional research is needed to assess the effect of $\mathrm{HCQ}$ in more patients and over multiple time points.

\section{References:}

[1] Hatemi G et al. 2018 update of the EULAR recommendations for the management of Behçet's syndrome. Ann Rheum Dis 2019;77:808-818

Disclosure of Interests: Floor Kerstens: None declared, Shreen Mohamed None declared, Ingrid Visman: None declared, Franktien Turkstra: None declared, Christopher Swearingen: None declared, Yusuf Yazici Consultant of: BMS, Celgene Corporation, Genentech, Sanofi - consultant, Consultant of: BMS, Celgene Corporation, Genentech, Sanofi - consultant

DOI: 10.1136/annrheumdis-2020-eular.4127

\section{AB0537 DIAGNOSTIC ACCURACY OF SYMPTOMS AND SIGNS FOR GIANT CELL ARTERITIS: SYSTEMATIC REVIEW AND META-ANALYSIS}

K. Van der Geest ${ }^{1}$, M. Sandovici ${ }^{1}$, E. Brouwer ${ }^{1}$, S. Mackie ${ }^{2}$. ${ }^{1}$ University Medical Center Groningen, Groningen, Netherlands; ${ }^{2}$ University of Leeds, Leeds, United Kingdom

Background: Making a correct diagnosis of giant cell arteritis (GCA) is critical given the potential complications of the disease and its therapy. Estimation of the clinical probability of GCA is challenging. Prediction models might be helpful, but have methodological and practical draw backs. One earlier meta-analysis described the diagnostic accuracy of symptoms and signs for a positive temporal artery biopsy [1]. In the latter study, the diagnostic accuracy of symptoms and signs might have been overestimated due to inclusion of case-control studies.

Objectives: To evaluate the diagnostic accuracy of symptoms and signs for GCA Methods: PubMed, EMBASE and the Cochrane Database were searched for relevant studies. Studies were eligible if: all patients were suspected of having GCA; either a temporal artery biopsy (TAB), imaging test, or clinical diagnosis was used as reference standard for GCA; a 2x2 table was available for at least one symptom, physical sign or routine laboratory test (i.e. the index tests). Case reports and case-control studies were excluded. The screening, full text review quality assessment with QUADAS-2 tool and data extraction were performed by two investigators. Hierarchical logistic regression modelling provided the pooled estimates of likelihood ratios with their 95\% confidence intervals. Likelihood ratios $<0.5$ (i.e. making GCA less likely) or $>2.0$ (i.e. making GCA more likely) were considered diagnostically relevant

Results: Out of 1359 reports screened, 59 studies were included in the study. These reports contained 13406 patients, including 3940 GCA patients. Most studies were retrospective, performed at tertiary centres and published after the prior meta-analysis [1]. TAB was the reference standard in 36 studies and a clinical diagnosis in 23 studies. Quality assessment revealed substantial risk of selection bias in the majority of studies. Studies using a clinical diagnosis were at risk of bias, as the reference standard might be influenced by the index tests (e.g. symptoms). Jaw claudication, limb claudication, temporal tenderness temporal artery abnormalities, especially arterial thickening or loss of pulse, and anterior ischemic optic neuropathy provided a positive likelihood ratio $>2.0$. None of the 19 symptoms and 7 physical signs evaluated, provided a negative likelihood ratio $<0.5$. An ESR $>60 \mathrm{~mm} / \mathrm{hr}$ and platelet count $>400^{*} 10^{9} / \mathrm{L}$ provided a positive likelihood ratio of $>2.0$. Absence of an elevated CRP level or ESR $>60 \mathrm{~mm} / \mathrm{hr}$ yielded a negative likelihood ratio of $<0.5$. Studies using a clinical diagnosis as reference standard reported higher positive likelihood ratios for jaw claudication, weight loss and PMR when compared to TAB studies. Absence of an elevated CRP provided a lower negative likelihood ratio in studies using the clinical diagnosis.

Conclusion: Few clinical findings may help to estimate the clinical probability of GCA. The presence or absence of any particular symptom or sign does not sufficiently rule out or rule in GCA. These findings highlight the need of additional tests (i.e. imaging, biopsy) in patients suspected of having GCA. 
References:

[1] Smetana GW, Shmerling $\mathrm{RH}$. Does this patient have temporal arteritis? Jama 2002 Jan 2;287(1):92-101.

Disclosure of Interests: Kornelis van der Geest Speakers bureau: Roche (2019), Maria Sandovici: None declared, Elisabeth Brouwer Consultant of: Roche (consultancy fee 2017 and 2018 paid to the UMCG), Speakers bureau: Roche (2017 and 2018 paid to the UMCG), Sarah Mackie Grant/research support from: Roche (attendance of EULAR 2019; co-applicant on research grant), Consultant of: Sanofi, Roche/Chugai (monies paid to my institution not to me) DOI: 10.1136/annrheumdis-2020-eular.2502

\section{AB0538 TAKAYASU'S ARTERITIS: CASE SERIES}

A. Vanegas ${ }^{1,2}$, F. Torres ${ }^{2}$, C. Muñoz $z^{1,2,3}$, D. Jaramillo ${ }^{1,2,3,4}$, L. Hernandez ${ }^{2}$, G. Vásquez ${ }^{2}$, M. Restrepo Escobar ${ }^{2}$, L. A. González ${ }^{2}$, I. Velásquez ${ }^{2} .{ }^{1}$ Hospital Universitario San Vicente Fundación, Medell in, Colombia; ${ }^{2}$ Universidad de Antioquia, Medellín, Colombia; ${ }^{3}$ IPS Universitaria, Servicios de Salud Universidad de Antioquia, Medellín, Colombia; ${ }^{4}$ Grupo de Epidemiología y Bioestadística del CES, Medellín, Colombia

Background: Takayasu's arteritis (TA) is most prevalent in women of childbearing age. Although its activity and risk of relapse are low during pregnancy, up to $40 \%$ of patients may have unfavorable obstetric outcomes and therefore it is important to know their clinical behavior.

Objectives: To describe the clinical features and obstetric outcomes of pregnant women with TA treated in a tertiary center.

Methods: Retrospective evaluation of medical records of 6 pregnancies in 6 women with TAs treated in a tertiary center in Medellin, Colombia between 2011-2018.

Results: Six women who were 17.5 (RI 9.25) years old at diagnosis and 24 (RI 8.25) years old at delivery, their disease duration were 5.5 (RI 10.5) years. Three patients had extensive aortic involvement classified as Numano type $\mathrm{V}$, two as type IIB and one as type I. At delivery, three patients were active and required immunosuppressants, five had high blood pressure, one developed preeclampsia in the second trimester, one had severe mitral and tricuspid insufficiency with decreased ejection fraction of the left ventricle; two had aneurysms (left subclavian artery and ascending aorta). There were two fetal deaths, one due to intrauterine growth restriction and placental insufficiency and another of unknown etiology; both patients with disease activity, extensive aortic condition and arterial hypertension; no pregnancy resulted in abortion or preterm birth. Five deliveries were by caesarean section by maternal indication; there was no aortic dissection, aneurismal rupture or cerebral hemorrhage (table).

Table. Patient's characteristics

\begin{tabular}{|c|c|c|c|c|c|c|}
\hline Patient & $\begin{array}{l}\text { Age at } \\
\text { diag- } \\
\text { nosis }\end{array}$ & $\begin{array}{l}\text { Age at } \\
\text { delivery }\end{array}$ & Clinical features & $\begin{array}{l}\text { Hata- } \\
\text { Numano } \\
\text { classifica- } \\
\text { tion }\end{array}$ & Maternal outcome & $\begin{array}{l}\text { Fetal } \\
\text { outcome }\end{array}$ \\
\hline 1 & 6 & 17 & $\begin{array}{c}\mathrm{HT} \text {, absence of left brachial } \\
\text { and radial pulses, } \mathrm{L} \text { carotid } \\
\text { and subclavian murmurs, } \\
\text { LVEF } 47 \%\end{array}$ & V & HT, C-section & $\begin{array}{c}\text { Term deliv- } \\
\text { ery, SGA }\end{array}$ \\
\hline 2 & 22 & 26 & $\begin{array}{c}\mathrm{HT} \text {, abscence of } \mathrm{L} \text { brachial } \\
\text { and radial pulses, } \mathrm{L} \text { carotid } \\
\text { and subclavian murmurs, } \\
\text { dyspnea, angina }\end{array}$ & $\begin{array}{l}\text { V } \\
\text { (plus pul- } \\
\text { monary) }\end{array}$ & $\mathrm{HT}$, vaginal birth & $\begin{array}{l}\text { Placental } \\
\text { insuffi- } \\
\text { ciency, } \\
\text { IUGR, fetal } \\
\text { death }\end{array}$ \\
\hline 3 & 14 & 38 & $\begin{array}{l}\mathrm{HT} \text {, abscence of } \mathrm{L} \text { brachial } \\
\text { and radial pulses, } \mathrm{L} \text { carotid } \\
\text { and subclavian murmurs, } \\
\text { intermittent claudication, } \\
\text { dyspnea, aortic regurgitation }\end{array}$ & IIB & HT, C-section & $\begin{array}{c}\text { Term deliv- } \\
\text { ery, SGA }\end{array}$ \\
\hline 4 & 18 & 24 & $\begin{array}{c}\mathrm{HT} \text {, malaise, abscence of } \mathrm{L} \\
\text { brachial and radial pulses, } \\
\text { intermittent claudication, } \\
\text { arthralgia }\end{array}$ & IIB & $\begin{array}{l}\text { Preeclampsia, } \\
\text { C-section }\end{array}$ & $\begin{array}{l}\text { Term deliv- } \\
\text { ery, SGA }\end{array}$ \\
\hline 5 & 17 & 22 & $\begin{array}{l}\text { Fever, malaise, intermittent } \\
\text { claudication, arthralgia }\end{array}$ & I & C-section & $\begin{array}{l}\text { Term deliv- } \\
\text { ery, SGA }\end{array}$ \\
\hline 6 & 21 & 24 & $\begin{array}{l}\mathrm{HT} \text {, abscense of bilateral } \\
\text { femoral, popliteal, tibial and } \\
\text { pedial pulses, headache, } \\
\text { dizziness, amaurosis }\end{array}$ & V & HT, C-section & Fetal death \\
\hline
\end{tabular}

HT: hypertension; L: left; LVEF: left ventricular ejection fraction; C-section: cesarean section; SGA: small for gestational age; IUGR: intrauterine growth restriction
Conclusion: Pregnant women with active disease and extensive aortic condition presented unfavorable obstetric results, suggesting that an inadequate control of vasculitis may lead to greater maternal-fetal complications.

\section{References:}

[1] Assad APL, da Silva TF, Bonfa E, Pereira RMR. Maternal and Neonatal Outcomes in 89 Patients with Takayasu Arteritis (TA): Comparison Before and After the TA Diagnosis. J Rheumatol. 2015 Oct;42(10):1861-4.

[2] Hidaka N, Yamanaka Y, Fujita Y, Fukushima K, Wake N. Clinical manifestations of pregnancy in patients with Takayasu arteritis: experience from a single tertiary center. Arch Gynecol Obstet. 2012 Feb;285(2):377-85.

Disclosure of Interests: None declared

DOI: 10.1136/annrheumdis-2020-eular.1246

\section{\begin{tabular}{|l|l}
\hline AB0539 URINARY INFLAMMATORY CELL ANALYSIS & UNA
\end{tabular} REFLECTS THE RENAL HISTOPATHOLOGY IN ANTI- NEUTROPHIL CYTOPLASMIC ANTIBODY-ASSOCIATED VASCULITIS}

Y. Wada $^{1,2}$, M. Sudo ${ }^{2}$, D. Kobayashi ${ }^{2}$, T. Kuroda ${ }^{2}$, I. Narita ${ }^{2}{ }^{1}$ Niigata Rinko Hospital, Department of Clinical Rheumatology, Niigata, Japan; ${ }^{2}$ Niigata University Graduate School of Medical and Dental Sciences, Division of Clinical Nephrology and Rheumatology, Niigata, Japan

Background: The anti-neutrophil cytoplasmic autoantibody (ANCA)- associated vasculitides (AAVs) include microscopic polyangiitis (MPA), granulomatosis with polyangitis (GPA), and eosinophilic granulomatosis with polyangitis (EGPA) These small-vessel vasculitides are characterized by necrotizing inflammation of the vessel wall, particularly affecting small arteries, arterioles, and capillaries in systemic organs, and the kidney is one of the most frequently involved organs. Although kidney biopsy is necessary for deciding the therapeutic protocol, it is invasive and is sometimes hard to perform biopsy because of patient's severe general condition. We have already reported that $\mathrm{T}$ cells and macrophages appear in the urine of patients with glomerulonephritis, accompanied by active cellular infiltration such as cellular crescent formation and diffuse interstitial cel infiltration, but not in the urine of patients with glomerulonephritis without the active inflammatory lesions.

Objectives: In this study, we examined the utility of urinary inflammatory cell analysis for accessing kidney histopathological findings in AAVs.

Methods: This was a cross-sectional, retrospective chart study. Thirty-six AAV patients who had been referred to Niigata University Hospital between 2002 and 2018, and performed percutaneous kidney biopsy and urinary inflammatory cell analysis, were participated in this study. Thirty-two patients had MPA, and 4 had GPA. The kidney biopsy findings were classified into Berden's classification (a method to categorize glomerular lesions into four classes) and Neumann's classification (a method to evaluate glomerular, tubulo-interstitial, and vascular lesions by using activity indexes and chronicity indexes). Flow-cytometric analysis of urinary inflammatory cells was performed for each subject. Numbers of urinary $\mathrm{T}$ cells or macrophages were determined by multiplying the number of viable cells in the gated mononuclear cell region in each sample by the percentage of urinary CD3-positive or CD14-positive cells in the population, respectively. The correlations between the results of both methods and the numbers of urinary inflammatory cells were examined using Kruskal-Wallis test and Spearmann's rank correlation coefficient. A p-value of $<0.05$ was taken to denote statistical significance.

Results: The numbers of urinary inflammatory cells showed a trend of increase in crescentic category without statistical significance in Berden's classification. Meanwhile, activity indexes had significant positive correlations with the number of urinary CD3-positive cells $(r=0.541, p=<0.001)$, CD14-positive cells $(r=$ $0.354, p=0.034)$, and total inflammatory cells $(r=0.449, p=0.006)$ in Neumann's classification.

Conclusion: The numbers of urinary inflammatory cells reflect the active lesions of kidney histopathological findings, and these results indicate the usefulness of urinary inflammatory cell analysis for assessment of kidney biopsy findings in patients with AAVs.

References:

[1] Berden AE, et al. J Am Soc Nephrol. 2010 Oct;21(10):1628-36. 2) Neumann I, et al. Nephrol Dial Transplant. 2005 Jan;20(1):96-104.

Disclosure of Interests: None declared

DOI: 10.1136/annrheumdis-2020-eular.1779

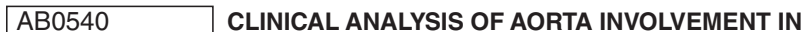 PATIENTS OF ANCA-ASSOCIATED VASCULITIS}

X. Chen', L. Wang' ${ }^{1}$ 'Sichuan Academy of Medical Sciences \& Sichuan Provincial People's Hospital \& Affiliated Hospital of Electronic Science and 